\title{
LA GLOBALIZACIÓN Y LA IDEA DE NACIÓN
}

P. Juan Bottasso, sdb.

Resumen

La palabra 'nación' ha asumido significados muy diferentes a lo largo de la historia, de tal manera que se vuelve indispensable aclarar algunos conceptos y hacer varias puntualizaciones, de otra manera se corre el riego de utilizarla con sentidos contradictorios y crear así serios malentendidos.

El sentido con el que hoy se la utiliza más frecuentemente es el que asumió en el siglo $\mathrm{XlX}$, en el ambiente cultural típico del romanticismo.

El fenómeno de la globalización vuelve a replantear ciertos interrogantes sobre el significado del vocablo. Cualquiera que pueda ser el uso que se le dé en el futuro, resultará siempre útil conocer el recorrido del concepto a lo largo de los siglos.

\section{La antigüedad}

Para afrontar cualquier argumento es indispensable un mínimo de retrospectiva histórica, porque todos los grandes movimientos del pensamiento humano son fruto de la evolución de etapas anteriores, que hay que conocer en sus rasgos esenciales.

Muy esquemáticamente recordaré como, a finales del siglo IV antes de Cristo, Alejandro Magno de Macedo- 
nia logró establecer la estructura imperial más imponente que, hasta entonces, la historia hubiera conocido: desde Grecia llegó a la India. Fue una construcción política que él no logró consolidar (murió con poco más de 30 años) pero que tuvo un influjo cultural impresionante, capaz de desafiar los siglos y extenderse por un área inmensa.

Mientras sus epígonos se disputaban el dominio del Mediterráneo oriental, se afianzó la potencia de Roma, caracterizada por un sólido entramado organizativo. El derecho y la ingeniería fueron su fortaleza. A través del primero, Roma logró administrar un conjunto de innumerables pueblos, portadores de culturas muy diferentes; con la segunda, por medio de carreteras y puentes, conectó las provincias más lejanas al centro. Muchas de sus calzadas, sus acueductos, sus foros, sus anfiteatros, subsisten y se utilizan hasta hoy.

Si partimos del año de la fundación de Roma (721 a.C.) y llegamos a la caída de Constantinopla, capital de la parte oriental (1454), contamos más de dos mil años: ningún imperio duró tanto.

Pero, como todo organismo viviente, también los imperios entran inexorablemente en la fase de la decadencia: corrupción, disolución de las costumbres, cosmopolitismo permisivo, luchas por el poder, debilitaron el coloso que finalmente no pudo resistir las presiones que, a lo largo de sus fronteras, comenzaron a ejercitar pueblos extraños.

Los romanos los llamaban bárbaros y los miraban con aire de superioridad. Pero se trataba de fuerzas nuevas y frescas, que, al penetrar en el territorio del imperio, trajeron una renovada vitalidad. Vándalos, Godos, Visigodos, Ostrogodos, Francos, Hunos... causaron destrucción y muerte, pero dejaron también los gérmenes de nuevas culturas. 
Por un largo periodo las comunicaciones se interrumpieron, los mares se llenaron de piratas y los caminos de salteadores; los intercambios se redujeron a su expresión mínima y las ciudades se despoblaron. En su lugar surgieron castillos amurallados. Había empezado el Medio Evo, la que fue llamada Edad Intermedia y tenebrosa entre dos periodos de esplendor.

\section{El universalismo medieval}

Es erróneo considerar oscuros aquellos siglos. En medio de los escombros de un mundo derrumbado iban brotando los retoños de algo nuevo, que llegaría hasta nosotros. Basta pensar en esos milagros de estética y de ingeniería que son las catedrales góticas.

El francés Jacques Le Goff, uno de los máximos especialistas en historia de la Edad Media, nos enumera una serie de bienes y objetos de los cuales les somos deudores: el molino, la brújula, la hora, el libro, el tenedor, las sábanas... Pero, sobre todo, él afirma sin vacilaciones que aquella fue una época de fe, pero también una época apasionada por la búsqueda de la razón. Le debemos algunas de las conquistas de las que Occidente aún anda orgulloso: la universidad, el Estado, la nación, los derechos de los individuos, la emancipación de la mujer, la lucha por la libertad de conciencia.

Evidentemente, la maduración de ideas que han marcado el avanzar de la historia, necesitan siglos para afirmarse y abrirse camino, en medio de resistencias y retrocesos.

La noche de Navidad del año 800, el Papa Esteban coronaba solemnemente en la basílica de San Pedro a Carlo Magno como emperador: renacía el imperio romano, pero con el carácter de 'sagrado': ya no eran el Senado 
y el pueblo romano los que le otorgaban la autoridad sino el Pontífice.

De esta manera se afianzaba el concepto de 'cristiandad', esa unidad político-religiosa, con un territorio bien definido y regentada por las dos 'espadas', la espiritualidad y lo temporal, un universalismo en que los dos poderes mantuvieron relaciones estrechas, pero conflictivas. Son emblemáticos los choques entre Gregorio VII y Enrique IV, Alejandro III y Federico II.

Pero se trataba de un universalismo con dimensiones demasiado extensas. Poco a poco se fueron delineando aquellas que después serían las comunidades nacionales. España fue la primera en alcanzar la conciencia de unidad, a través de una lucha contra los Moros, que duró casi ocho siglos. El largo enfrentamiento contra una realidad cultural y religiosa diferente reforzó la idea de la propia identidad. Otros países siguieron a España, como Francia y, casi de inmediato, Inglaterra. Flandes recorrió el mismo camino luchando fieramente contra el español Duque de Alba. Lo que rompió definitivamente la homogeneidad universalística de la Europa Cristiana fue la Reforma Protestante. La traducción de las Sagradas Escrituras a los idiomas vernáculos tuvo repercusiones enormes.

\section{La nación moderna}

Intervinieron también otros factores: los descubrimientos geográficos, que acentuaron la idea de la diversidad de los pueblos; el fortalecimiento de la administración estatal centralizada; la preocupación de auto legitimarse, investigando las propias raíces históricas. De esta manera fue formándose el concepto de nación, percibida como una colectividad que tiene en común historia, lengua y costumbres. 
Fue exactamente en el periodo en que comenzó a consolidarse esta visión, es decir, al comienzo de la época de los grandes descubrimientos y de la formación de los primeros estados nacionales, que Niccoló Machiavelli, trabajando en Florencia a servicio de los Medici, redactó El Príncipe.

La visión que se tiene de este pensador es bastante superficial y reductiva. Se lo considera a menudo como un maestro de cinismo y doblez, para quien cualquier medio es legítimo, con tal de alcanzar el fin, es decir conseguir, conservar y aumentar el poder.

Pero El Príncipe no es un simple manual de sugerencias perversas para gobernantes sin escrúpulos. $\mathrm{Si}$ fuera así no habría dejado de leerse a través de siglos y no seguiría siendo un texto estudiado en la actualidad en las facultades de derecho y de ciencias políticas. Lo que hace Machiavelli es desacralizar, secularizar la política, afirmar su autonomía y describir descarnadamente el funcionamiento del poder. Es decir, no es un breviario de consejos, sino una radiografía despiadada de las pasiones humanas en el ejercicio del poder.

El concepto de 'nación' de la época del Renacimiento tuvo un peso más cultural que político. Es con Jean Jacques Rousseau y la Revolución Francesa que la 'nación', luchando contra los privilegios del rey y de la aristocracia, se afirma como sujeto político, que alcanza a todos los ciudadanos. Entendida como comunidad de individuos que deciden asociarse libremente, llega a ser artífice de una nueva legitimidad, alternativa al poder absoluto del rey.

El romanticismo hace del concepto de nación un poderoso instrumento de integración cultural y míticosimbólico, para sociedades en proceso de modernización. En Europa son típicos los casos de Alemania e Italia. En Polonia fermentan movimientos de independencia y uni- 
ficación, que fraguarán sólo después de la Primera Guerra Mundial. En los Balcanes la lenta disolución del imperio otomano da origen a un abanico de estados nacionales. Algo parecido había ocurrido con anterioridad en América Latina, al fraccionarse el imperio ibérico. Decenas de países se esforzaron por afirmar su diversidad cultural e histórica frente a los demás, redescubriendo un pasado, a veces mitificado. Pensemos, por ejemplo en la utilización instrumental de la idea del Reino de Quito, en el caso del Ecuador. También el largo periodo de tensión y conflicto con el vecino Perú, contribuyó a consolidar la identidad del país. Los escudos de armas, los himnos nacionales, la retórica de los discursos oficiales y de los libros de texto, los monumentos que adornan plazas y parques, son un testimonio palpable de esta realidad.

Mientras tanto, en ciertas áreas, especialmente en Alemania a fines del siglo XIX y en las primeras décadas del siguiente, se abre paso una visión absolutista de nación. Ella exalta los vínculos culturales, pero, sobre ellos, afirma la primacía de lo étnico. La pertenencia se define en base a la sangre, aún por encima de la voluntad de las personas. De aquí a elevar el racismo a política de estado no hay más que un paso. La nación es exaltada sobre todos los valores, aun sobre la libertad individual.

Esta evolución negativa del nacionalismo produjo consecuencias apocalípticas; dos guerras mundiales en tres décadas causaron decenas de millones de muertos.

La reacción a estos excesos ha conducido a la situación que estamos viviendo. No son pocos los que consideran los estados nacionales bajo una luz negativa: mantienen fronteras anacrónicas y justifican estructuras militaristas que succionan los presupuestos y enturbian las aguas de la política con continuas intromisiones. Los que así ven las cosas proponen articular unidades mucho más 
amplias, que reduzcan los enfrentamientos y faciliten los intercambios.

En el campo económico este proceso ya se está dando. Se trataría de pasar al área política como, trabajosamente, intenta hacer Europa. En América Latina los proyectos no faltan, pero el camino aún se ve diseminado de enormes obstáculos y de poderosas fuerzas centrífugas.

Como puede verse, esta reflexión se ha centrado en el Occidente, y es natural, porque estamos ubicados en esta parte del mundo. Muy distintas serían las reflexiones si nos hubiéramos ocupado de Asia, con sus milenarias culturas de India, China y Japón. Pero la evolución de la organización política de aquellos pueblos, ha tenido un influjo mínimo sobre las ideas de nuestra área cultural.

Con la globalización el escenario está en pleno movimiento. Nuevos retos y nuevas propuestas se están presentando. Contestar a estos desafíos no es tarea de los historiadores, sino de los políticos y politólogos.

Su visión debe apuntar al futuro, pero no será completa y realista, si no tendrá en cuenta la estrecha relación del futuro con el pasado.

\section{Conclusión}

El imparable proceso globalizador evidentemente está teniendo consecuencias enormes sobre la configuración de los estados y sus estructuras.

Las fronteras ya no se consideran 'sagradas' como un tiempo y los gobiernos de los diferentes países se ven obligados a ceder ciertas prerrogativas a favor de entidades supranacionales, no sólo en el campo económico, sino en el de la defensa, la seguridad, la movilidad de las personas, la comunicación. Los presidentes pasan una parte notable del tiempo fuera de su país, en reuniones de diferentes ti- 
pos, para concordar políticas comunes. Los mandatos de los tratados internacionales firmados por un país prevalecen sobre los de sus mismas constituciones.

Sin olvidar otro hecho indiscutible: muchas empresas transnacionales tienen presupuestos y, por ende, un peso específico, mucho mayor que aquel de que disponen un gran número de naciones, siempre menos 'soberanas'.

Contemporáneamente, como reacción a esta tendencia, hay una gran sensibilidad para redescubrir los valores locales, la memoria, las tradiciones, los idiomas, las fiestas, el folklore tradicional.

Es imposible adivinar a dónde llevará este doble movimiento, pero es seguro que acabará conformando un mundo muy diferente del que conocemos.

\section{Bibliografía}

ALTERNATIVES SVD: VOL. 17 - 2010

2010 Racisme, entre exclusión social y peur identitaire, Louvain: Ed. Syllepse.

ÁLVAREZ GONZÁLEZ, Freddy

2000 Las derivas de la alteridad, Ed. Del Aula.

ATTALI, Jacques

2006 Breve historia del futuro, Buenos Aires: Paidós.

BAUMAN, Zygmunt

2007 Modus Vivendi, Bari: Ed. Literza.

HUNTINGTON, Samuel

2004 Quienes somos, Buenos Aires: Ed. Paidós.

SARTORI, Giovanni

2002 Pluralismo, Multiculturalismo e Estranei, Rizzoli, Milano: Ed Biblioteca Universale. 